CASE REPORT

\title{
A pituitary carcinoma secreting TSH and prolactin: a non-secreting adenoma gone awry
}

\author{
Rebecca L Brown, Tariq Muzzafar ${ }^{1}$, Robert Wollman ${ }^{1}$ and Roy E Weiss \\ Thyroid Study Unit, Department of Medicine, University of Chicago, 5841 S Maryland Ave, Mail Code 3090, Chicago, Illinois 60645, USA and \\ ${ }^{1}$ Department of Pathology, University of Chicago, Chicago, Illinois 60637, USA \\ (Correspondence should be addressed to R E Weiss; Email: rweiss@medicine.bsd.uchicago.edu)
}

\begin{abstract}
To our knowledge, only one case of a TSH-secreting carcinoma has previously been reported. We describe here a second patient with a pituitary carcinoma producing TSH and prolactin (PRL). A 37-year-old male underwent a left frontotemporal craniotomy in 1996 for a sellar mass. Except for mildly increased PRL and elevated $\alpha$-subunit, hormone evaluation was normal. Pathologic examination revealed a chromophobe adenoma with increased mitotic forms. The patient completed a course of external beam radiation to the pituitary and was prescribed L-thyroxine, bromocriptine, and hydrocortisone. He was lost to follow-up but did well for 6 years, until 2002, when he presented with TSH-dependent thyrotoxicosis and hyperprolactinemia. The patient was started on bromocriptine and propylthiouracil and was, again, lost to follow-up. In 2004, 9 years after his initial presentation, he presented after falling. Magnetic resonance imaging showed two brain masses with associated midline shift. Emergent resection of the larger mass revealed a pituitary cancer with positive staining for PRL, but not for TSH. Nine months later, the patient underwent further debulking of metastatic disease. Although development of a carcinoma from a pituitary adenoma is very rare $(<0.5 \%)$, macroadenomas that become hormonally active should be suspect for transformation into pituitary cancer.
\end{abstract}

European Journal of Endocrinology 154 639-643

\section{Introduction}

Pituitary carcinomas are rare tumors, with only 140 cases described in the English literature (1). While the majority of reported cases secreted either adrenocorticotropin (ACTH) or prolactin (PRL), only one described tumor produced thyrotropin (TSH) (2). We report a patient with a non-functioning tumor that transformed into a PRL- and TSH-secreting carcinoma. This case illustrates that pituitary tumors can alter hormone production and that tumors exhibiting changes should be evaluated for transformation to carcinomas.

\section{Case report}

A 37-year-old male with a history of alcohol abuse presented to the emergency room in 1995 with seizures. Magnetic resonance imaging (MRI) of the brain revealed a $2 \times 2 \times 3 \mathrm{~cm}$ sellar mass with compression of the optic chiasm (Fig. 1A).

Hormonal evaluation at the time of admission was significant for a mildly elevated PRL of $146 \mathrm{ng} / \mathrm{ml}$ (normal range $0-15 \mathrm{ng} / \mathrm{ml}$ ). Thyroid function tests were within normal limits (TSH, 2.7 (normal range $0.3-3.8 \mu \mathrm{U} / \mathrm{ml}$ ), free thyroxine index (FTI), 7.7 (normal range 6-10.5 units)). Serum leutinizing hormone (LH) was $2.2 \mathrm{IU} / \mathrm{l}$, follicle-stimulating hormone (FSH) was $3.5 \mathrm{IU} / \mathrm{l}$, and morning cortisol was $14.5 \mu \mathrm{g} / 100 \mathrm{ml}$. Total testosterone was low at $225 \mathrm{ng} / \mathrm{dl}$ (normal range 312-1240 $\mathrm{ng} / \mathrm{dl}$ ), and serum $\alpha$-subunit was elevated at $46.8 \mathrm{ng} / \mathrm{ml}$ (normal value $<1$ )

The patient was diagnosed with a non-functioning pituitary tumor secreting $\alpha$-subunit. The elevated PRL was thought to be from stalk compression. He underwent a left frontotemporal craniotomy to debulk the lesion. The surgery resulted in vision loss, which failed to improve. Pathology revealed a chromophobe adenoma with increased mitotic forms; staining for PRL, growth hormone (GH), TSH, FSH, and LH were negative.

The patient completed a course of external beam radiation to the pituitary and was prescribed L-thyroxine $\left(\mathrm{L}-\mathrm{T}_{4}\right)$, bromocriptine, and hydrocortisone. He was lost to follow-up but did well for 6 years, until January 2002, when he presented with weight loss, diaphoresis, 

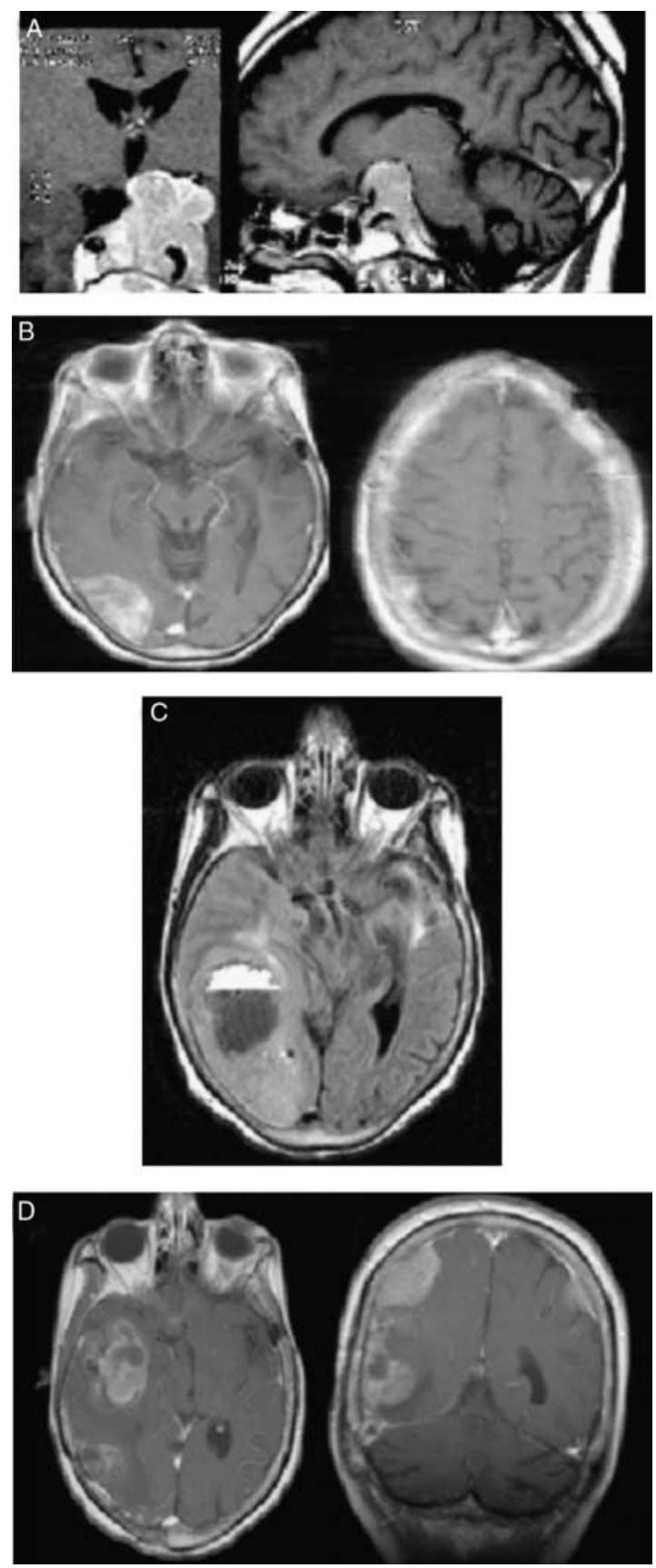

Figure 1 Serial T1-weighted MRI of pituitary and brain. (A) In 1995, a $2 \times 2 \times 3$ sellar mass with encasement of the left carotid artery and compression of the optic chiasm was visible. Coronal section (left) and sagital view (right). (B) In 2003, two masses were seen; $4.2 \times 2.5 \mathrm{~cm}$ lesion in the right temporo-occipital lobe (right) and $1.5 \times 1.5 \mathrm{~cm}$ in the right parietal lobe (left). (C) In 2004 , the larger brain mass measured $6.9 \times 4.2 \mathrm{~cm}$ with signs of internal hemorrhage and/or internal necrosis. Mass effect and midline shift are present. (D) In 2005, the patient presented in status epilepticus. Both coronal (left) and sagital (right) images show multiple metastatic lesions, the largest in the right temporal lobe. hyperphagia and goiter. He was taking no medications. Biochemical studies revealed TSH-dependent hyperthyroidism, with serum TSH at $9.9 \mu \mathrm{U} / \mathrm{ml}$ and an FTI of 43.6. PRL was elevated at $354 \mathrm{ng} / \mathrm{ml}$ and total testosterone measured $<20 \mathrm{ng} / \mathrm{dl}$. A dedicated pituitary MRI was suspicious for residual disease in the pituitary; the entire brain parenchyma was not evaluated. He was prescribed hydrocortisone, propylthiouracil (PTU), and bromocriptine. His thyrotoxic symptoms were improved at a clinic appointment 2 weeks later.

The patient was again lost to follow-up until he presented to the emergency room 1 year later in February 2003 with altered mental status; he was taking no medications. A brain MRI showed residual disease in the pituitary. In addition, two lesions with radiographic appearances suggestive of 'meningiomas' were seen; the first, in the right temporo-occipital area measured $4.2 \times 2.5 \mathrm{~cm}$ and the second, in the right parietal lobe, was $1.5 \times 1.5 \mathrm{~cm}$ (Fig. 1B).

Serum TSH measured $53 \mu \mathrm{U} / \mathrm{ml}$ and the FTI was 22 . PRL was $>1200 \mathrm{ng} / \mathrm{dl}$ and $\alpha$-subunit had increased to $96 \mathrm{ng} / \mathrm{ml}$. Thyrotropin-releasing hormone stimulation $(100 \mu \mathrm{g})$ raised serum PRL levels from 1241 to $1650 \mathrm{ng} / \mathrm{ml}$ but failed to increase TSH (Table 1). Insulin-induced hypoglycemia (Table 1) showed no increase in GH and a mild increase in cortisol $(3.6-7.6 \mu \mathrm{g} / 100 \mathrm{ml})$, suggestive of secondary adrenal insufficiency and GH deficiency. The patient was re-started on bromocriptine, PTU, and hydrocortisone. Before further treatment could be initiated, he was lost to follow-up.

Eight months later, in November 2003, the patient presented to the emergency room again with altered mental status and thyrotoxicosis. He was taking no medications. ${ }^{131}$ I thyroid ablation was performed to control his symptoms. He failed to come to any of his follow-up appointments.

Ten months later, in September 2004, the patient was brought to the emergency room after falling down the stairs. A brain MRI (Fig. 1C) showed interval increase in the two right lobe lesions. The larger $(8.1 \times 5.5 \mathrm{~cm})$ showed areas of hypodensity suspicious for internal necrosis and/or hemorrhage. There was significant associated mass effect. The second lesion measured $3.5 \times 3.5 \mathrm{~cm}$. Emergent resection of the larger mass revealed a pituitary cancer with MIB-1 (a cell proliferation marker that recognizes the KI-67 antigen) immunoreactivity $>15 \%$, and positive staining for PRL and synaptophysin, but not for TSH (Fig. 2).

Laboratory investigation revealed hypothyroidism (free $\mathrm{T}_{4}$ by dialysis $0.4 \mathrm{ng} / \mathrm{dl}$ (normal range $1.0-2.0 \mathrm{ng} / \mathrm{dl}$ )) and hyperprolactinemia (PRL, $649 \mathrm{ng} / \mathrm{ml}$ ). L-T 4 , cabergoline, and hydrocortisone were prescribed and the patient was discharged home.

At a follow-up appointment 2 weeks later, the patient had improved mental status. He was euthyroid 
Table $1 \mathrm{TRH}$ stimulation test and insulin-induced hypoglycemia test. Insulin (0.1 units/kg) and TRH (100 $\mu$ g) given at time zero. TSH, cortisol, GH, PRL and serum glucose were measured every $15 \mathrm{~min}$ for $60 \mathrm{~min}$, then every $30 \mathrm{~min}$ until $120 \mathrm{~min}$.

\begin{tabular}{|c|c|c|c|c|c|c|c|c|}
\hline & \multicolumn{8}{|c|}{ Time (min) } \\
\hline & -30 & 0 & 15 & 30 & 45 & 60 & 90 & 120 \\
\hline $\mathrm{TSH}(\mathrm{mcU} / \mathrm{ml})$ & 26 & 25 & 24 & 25 & 25 & 24 & 22 & 22 \\
\hline $\mathrm{T}_{4}(\mathrm{mcg} / \mathrm{dl})$ & 20.2 & - & - & - & - & - & - & 18.4 \\
\hline FTI & 27.0 & - & - & - & - & - & - & 19.5 \\
\hline Cortisol (mcg/100 ml) & 3.6 & 3.2 & 3.4 & 2.9 & 6.3 & 7.6 & 7.1 & 6.1 \\
\hline $\mathrm{GH}(\mathrm{ng} / \mathrm{ml})$ & 0.2 & 0.2 & 0.2 & 0.2 & 0.2 & 0.2 & 0.2 & 0.3 \\
\hline PRL (ng/ml) & 1241 & 1230 & 1380 & 1530 & 1650 & 1613 & 1234 & 1254 \\
\hline Serum glucose (mg/dl) & 90 & 91 & - & $<20$ & 30 & 35 & 52 & 70 \\
\hline
\end{tabular}

on $\mathrm{L}_{-} \mathrm{T}_{4}$ with decreasing $\mathrm{PRL}$ on cabergoline. He showed continued clinical and laboratory improvement at two subsequent office visits despite a repeat MRI which showed several new small areas of metastatic disease. Palliative radiation therapy was recommended, but the patient failed to come to his appointments.

In June 2005, the patient was brought to the emergency room in status epilepticus. His seizures were controlled with benzodiazepines and phenytoin. A brain MRI revealed multiple large dural-based lesions (Fig. 1D) with evidence of transtentorial herniation. High dose steroids were initiated.

The patient underwent surgical debulking of the right temporal lesion. Pathology of the metastatic lesion was consistent with recurrent tumor, but immunohistochemical staining with antibody against pituitary hormones, including PRL, was negative. MIB-1 antibody labeled more than $50 \%$ of the tumor cell nuclei.

Laboratory investigation revealed euthyroidism (free $\mathrm{T}_{4}$ by dialysis $1.2 \mathrm{ng} / \mathrm{dl}$ ) and worsening hyperprolactinemia $(1354 \mathrm{ng} / \mathrm{ml})$. ${\mathrm{L}-\mathrm{T}_{4}}_{4}$ and hydrocortisone were continued and bromocriptine was started.

The family agreed to have the patient placed in a long-term care nursing facility. He received a full course of radiation and consistently took his cabergoline with resolution of the seizures.

\section{Discussion}

The diagnosis of pituitary cancer is extremely rare, accounting for $0.1-0.5 \%$ of pituitary tumors (3). The diagnostic criteria itself are widely debated; no histological, immunohistochemical, or electron microscopal findings reliably distinguish pituitary adenomas from carcinomas. The current consensus in the literature supports the presence of metastases to diagnose carcinoma.

Our patient was similar to previous case reports of pituitary carcinoma for several reasons. The literature suggests that the primary tumor is typically diagnosed in the fourth decade; our patient was 37 years old at presentation. Furthermore, the average time between diagnosis of a pituitary adenoma to the development of metastases averages 7 years, although in PRL-producing tumors the mean is shorter (4.7 years) (4). Our patient presented 9 years after his primary tumor was resected, although the reccurrence had likely gone undiagnosed for some time. Thirdly, our patient's initial tumor pathology had frequent mitotic figures and prominent nucleoli, two features associated with, although not completely indicative of, more aggressive tumor behavior (4).

Our patient was unique, in many respects, to previous reports of pituitary carcinoma. His laboratory

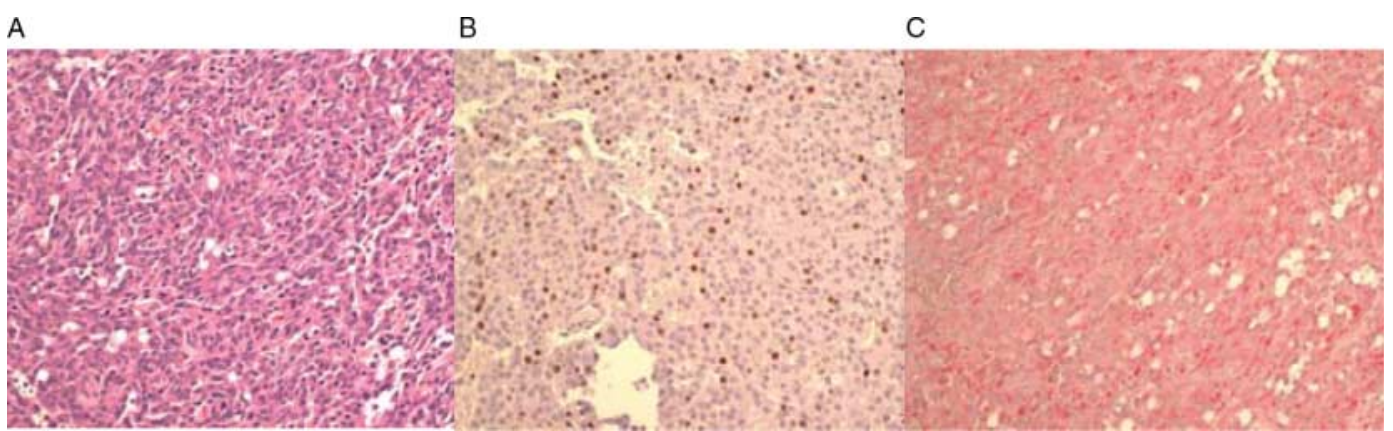

Figure 2 (A) Low power view of hemotoxylin and eosin-stained specimen resected in 2004. Pathology revealed sheets of neuroendocrine cells with nuclear enlargement with distinct nucleoli; this was similar in appearance to the pathological sample resected in 1995. (B) MIB-1 labeling index revealed $>15 \%$ staining, suggestive of cell proliferation. (C) Immunohistochemistry with antibody against PRL showed high reactivity (red reaction product). 
data over the progression of his disease are summarized in Table 2. Both his clinical course and endocrine evaluation support the diagnosis of a PRL- and TSHsecreting pituitary carcinoma. Although we have been unable to confirm the latter diagnosis through immunohistochemistry, an inappropriately high TSH, an elevated $\alpha$-subunit, and an $\alpha$-subunit/TSH molar ratio of greater than 1 (depending on the TSH and gonadotropin levels (5)) all support the diagnosis of a TSHsecreting tumor (2). In our patient, the $\alpha$-subunit/TSH ratio was calculated at greater than 18 .

It is possible that the resected metastatic tumor failed to stain with anti-TSH $\beta$-subunit immunoglobulin because the TSH may have been secreted from residual pituitary disease. These metastatic lesions represent a less-differentiated neuroendocrine tumor, now unable to make TSH. Likewise, the first resected metastatic tumor stained with antibody against PRL whereas the second metastatic tumor did not. This also suggests that the tumor further de-differentiated as it progressed. Given that the patient's PRL was greater than $1300 \mathrm{ng} / \mathrm{ml}$ at the time the second metastatic lesion was removed, it is presumed that some of the metastatic lesions still retained the ability to secrete PRL.

Although the molecular basis of pituitary carcinoma has not been fully elucidated, many genetic defects have been described. X-inactivation analysis has shown that pituitary tumors are derived from monoclonal expansion of a single transformed cell (6). The accumulation of genetic aberrations in oncogenes and/or tumor suppressor genes within this monoclonal cell population may transform benign lesions into malignant ones. Pituitary carcinoma likely develops in a stepwise fashion involving dysregulation of cell growth, differentiation, and hormone production (7).

This patient's clinical course supports the theory that pituitary carcinoma results from the accumulation of multiple genetic defects. At presentation, the patient's tumor was thought to be hormonally silent. However, after his reccurrence, the initial pathology specimen was restained and was subsequently found to be mildly positive for PRL. As his disease progressed, the tumor transformed into either a TSH-/PRL-secreting adenoma or carcinoma. Following thyroid ablation, he became hypothyroid and, as a result of poor medical compliance, never received thyroid hormone replacement. This, in turn, may have stimulated tumor growth from loss of negative feedback and allowed for de-differentiation, loss of TSH secretory function, and development of gross metastases. Following further growth, PRL secretory function may also have been compromised.

It has been well described that neuroendocrine tumors are able to produce more than one hormone and that their hormone secretion can change over time (8). Sironi et al. (9) presented immunohistochemical evidence of a prolactinoma with associated high serum cortisol levels which transformed into a mixed ACTHPRL-GH carcinoma. In addition, the only other published case of a TSH-secreting pituitary carcinoma, described by Mixson et al. in 1993 (2), also documented a change in hormone production. Similar to our patient, this report describes a woman who was euthyroid at initial presentation with a pituitary adenoma. It was not until 5 years later that she was diagnosed with central hyperthyroidism and found to have reccurrence of her pituitary disease. In this case, however, immunohistochemistry with anti-TSH- $\beta$ immunoglobulin confirmed her biochemical data (2).

Reviews of previously reported cases of pituitary carcinoma have failed to clearly differentiate pituitary adenomas from carcinoma on the clinical, radiographic, or histochemical criteria at the time of diagnosis. The size of our patient's adenoma, in addition to the high number of mitoses and elevated MIB-1 staining (although not available in 1996) were possibly predictive of a more aggressive tumor (4). A few cases have shown that a sustained elevation in $\alpha$-subunit may be associated with a worse outcome $(1,10)$. The patient described in the first reported case of TSH-secreting pituitary carcinoma had an $\alpha$-subunit as high as $125 \mathrm{ng} / \mathrm{ml}$, higher than seen in TSH-secreting adenomas; this value decreased as her disease progressed, presumably due to de-differentiation of metastatic disease (2). In our patient, the peak $\alpha$-subunit was $96 \mathrm{ng} / \mathrm{ml}$. Given the rarity of pituitary carcinoma, the diagnostic value of the elevation in $\alpha$-subunit is not known. These data suggest, however, that the $\alpha$-subunit in patients with TSH-secreting lesions should be monitored closely.

Table 2 Summary of relevant endocrinology data at initial diagnosis (September 1995) and at follow-up.

\begin{tabular}{|c|c|c|c|c|c|c|c|}
\hline & \multirow[b]{2}{*}{ Normal values } & \multicolumn{6}{|c|}{ Clinical event and date } \\
\hline & & $\begin{array}{c}\text { Presents with } \\
\text { seizure } \\
\text { (Sept 1995) }\end{array}$ & $\begin{array}{l}\text { Thyrotoxic } \\
\text { symptoms } \\
\text { (Jan 2002) }\end{array}$ & $\begin{array}{c}\text { Altered } \\
\text { mental status } \\
(\text { Feb 2003) }\end{array}$ & & $\begin{array}{l}\text { Presents } \\
\text { after falling } \\
\text { (Sept 2004) }\end{array}$ & $\begin{array}{c}\text { Status } \\
\text { epilepticus } \\
\text { (June 2005) }\end{array}$ \\
\hline $\mathrm{TSH}(\mathrm{mcU} / \mathrm{ml})$ & $0.3-3.8$ & 2.7 & 9.9 & 53 & 드 & 8.4 & 14 \\
\hline $\mathrm{T}_{4}(\mathrm{mcg} / \mathrm{dl})$ & $5.0-11.6$ & 6.2 & 20.1 & 15.2 & $\underline{\bar{\sigma}}$ & 2.6 & 8.6 \\
\hline FTI & $6.0-10.5$ & 7.7 & 43.6 & 22 & $\frac{\overline{0}}{\sigma}$ & 4.1 & 8.7 \\
\hline Free $T_{4}$ by dialysis $(n g / d l)$ & $1.0-2.0$ & & 8.3 & & 0 & 0.4 & 1.2 \\
\hline $\mathrm{PRL}(\mathrm{ng} / \mathrm{ml})$ & $0-15$ & 146 & 354 & 1200 & 은 & 649 & 1354 \\
\hline$\alpha$-subunit (ng/ml) & 1 & 46.8 & & 96 & 彥 & 32 & \\
\hline
\end{tabular}


This case further reminds us that radiographic studies have shortcomings and cannot be substituted for tissue diagnosis. MRI scanning performed in 2003 showed two new lesions with radiographic appearances of 'meningiomas.' Dural sites of metastases mimicking meningiomas have previously been described in the literature (11). Given his problems with non-compliance, earlier recognition of metastatic disease may not have altered this patient's course. However, this finding illustrates that all central nervous system lesions in patients with a history of pituitary tumors should be evaluated for metastatic lesions.

This case illustrates that a non-functioning pituitary tumor can transform into a secreting carcinoma. Although carcinoma is usually thought of as a dedifferentiated state, that may not be entirely accurate. Our patient's tumor initially became more differentiated, as demonstrated by gaining secretory function, as it transformed into a more aggressive state. As the disease progressed, the tumor then de-differentiated. This suggests that macroadenomas that become hormonally active should be closely investigated for transformation into pituitary cancer.

\section{Acknowledgements}

This work was supported by NIH grants RR18372, RR00055, and DK07011.

\section{References}

1 Ragel BT \& Couldwell WT. Pituitary carcinoma: a review of the literature. Neurosurgery Focus 200416 1-9.

2 Mixson AJ, Friedman TC, Katz DA, Feuerstein IM, Taubenberger JK, Colandrea JM, Doppman JL, Oldfield EH \&
Weintraub BD. Thyrotropin-secreting pituitary carcinoma. Journal of Clinical Endocrinology and Metabolism 199376 529-533.

3 Kaltsas GA, Nomikos P, Kontogeorgos G, Buchfelder M \& Grossman AB. Clinical review: Diagnosis and management of pituitary carcinomas. Journal of Clinical Endocrinology and Metabolism 200590 3089-3099.

4 Pernicone PJ, Scheithauer BW, Sebo TJ, Kovacs KT, Horvath E, Young WF Jr, Lloyd RV, Davis DH, Guthrie BL \& Schoene WC. Pituitary carcinoma: a clinicopathologic study of 15 cases. Cancer 199779 804-812.

5 Beck-Peccoz P, Brucker-Davis F, Persani L, Smallridge RC \& Weintraub BD. Thyrotropin-secreting pituitary tumors. Endocrine Reviews 199617 610-638.

6 Shimon I \& Melmed S. Genetic basis of endocrine disease: pituitary tumor pathogenesis. Journal of Clinical Endocrinology and Metabolism 199782 1675-1681.

7 Farrell WE, Talbot JA, Bicknell EJ, Simpson D \& Clayton RN. Genomic sequence analysis of a key residue (Arg183) in human G alpha $\mathrm{q}$ in invasive non-functional pituitary adenomas. Clinical Endocrinology 199747 241-244.

8 Miehle K, Tannapfel A, Lamesch P, Borte G, Schenker E, Kluge R, Ott RA, Wiechmann V, Koch M, Kassahun W, Paschke R \& Koch CA. Pancreatic neuroendocrine tumor with ectopic adrenocorticotropin production upon second recurrence. Journal of Clinical Endocrinology and Metabolism 200489 3731-3736.

9 Sironi M, Cenacchi G, Cozzi L, Tonnarelli G, Iacobellis M, Trere D \& Assi A. Progression on metastatic neuroendocrine carcinoma from a recurrent prolactinoma: a case report. Journal of Clinical Pathology $200255148-151$.

10 Kaltsas GA \& Grossman AB. Malignant pituitary tumours. Pituitary $1998169-81$.

11 McCutcheon IE, Pieper DR, Fuller GN, Benjamin RS, Friend KE \& Gagel RF. Pituitary carcinoma containing gonadotropins: treatment by radical excision and cytotoxic chemotherapy: case report. Neurosurgery $2000461233-1239$.

Received 11 November 2005

Accepted 16 December 2005 